\title{
Unfolding Consumer Impulsivity: An Existential- Phenomenological Study of Consumers with Attention Deficit Disorder
}

\author{
Carol Kaufman-Scarborough \\ Rutgers University \\ Judy Cohen \\ Rider University
}

\begin{abstract}
This article attempts to unfold consumer impulsivity by gathering in-depth stories from persons whose impulsivity is a lifetime trait because of their attention deficit disorder (ADD/ADHD). The manuscript provides overviews of impulsivity, ADD, and impulsive consumer behavior. Insights into possible consumer-behavior challenges are offered from an information-processing perspective. Through thematic analysis of the respondents' lifetime stories, this study helps illuminate the black box of the consumer's mind with respect to impulsive consumption, by relating impulsive consumer behavior to specific problems in information processing. As such, it not only contributes to understanding of the consumer behavior of those with ADD, but also presents a kinder and gentler picture of consumers who are dealing with information overload and frustration, rather than what might be a more common stereotype of consumers who are simply out of control. (ㅇ 2004 Wiley Periodicals, Inc.
\end{abstract}




\section{INTRODUCTION}

Consumer researchers traditionally try to examine and understand numerous aspects of consumer behavior, such as individuals' abilities to evaluate products, to select and organize information in the retail environment, and to process information to make satisfactory decisions (Capon \& Davis, 1984; Coupey, 1994; MacInnis, Moorman, \& Jaworski, 1991). However, it is well known that rigorous and highly organized processing may characterize only part of consumer behavior in the marketplace. In reality, consumers are also found to be impulsive (Beatty \& Ferrell, 1998; Cobb \& Hoyer, 1986; Dholakia, 2000; Rook \& Fisher, 1995), distractible (AriasBolzmann, Chakraborty, \& Mowen, 2000; Lord \& Burnkrant, 1993), reliant on incomplete and/or irrelevant information (Johnson \& Levin, 1985; Kivetz \& Simonson, 2000; Meyvis \& Janiszewski, 2002; Ross \& Creyer, 1992), and in some cases, addicted to compulsive shopping (Nataraajan \& Goff, 1992; O'Guinn \& Faber, 1989). Impulses may be moderated by cognitive evaluation (Dholakia, 2000), unless self-control failure enables unplanned, spontaneous purchases to occur (Baumeister, 2002).

The intent of the present manuscript is to extend recent work on consumption impulsiveness (Beatty \& Ferrell, 1998; Dholakia, 2000; Rook \& Fisher, 1995) by examining self-reports from persons whose impulsivity appears to be a lifetime trait due to their attention deficit disorder (ADD). As researchers, the authors were intrigued with the steady stream of students and colleagues who report experiencing impulsive buying as routine. Upon more in-depth questioning, one variable consistently emerged in common-attention deficit disorder. Drawing on recent studies incorporating the impulsivity trait into formal empirical models, this study investigates the actual experiences of persons for whom impulsiveness is a documented and long-term trait to further unfold this construct. That is, an existential-phenomenological approach is used to examine impulsivity as it is lived in day-to-day shopping experiences (see Thompson, Locander, \& Pollio, 1989, for a detailed review of this approach).

One of the major characteristics of attention deficit disorder (ADD) or attention deficit-hyperactivity disorder (ADHD) is impulsiveness, together with several other sensory-related characteristics. ADD can be described through the experiences of persons who have it (ADDers), who feel as if they are bombarded with many stimuli. It can be described in a clinical fashion, such as a "neurobiological disability, characterized by attention skills that are developmentally inappropriate, impulsivity, and in some cases, hyperactivity" (CHADD, Factsheet 1). Understanding of the neurobiological basis for ADD has been furthered by a 1990 landmark study by Zametkin et al. (1990). They utilized brain imaging to examine the actual operation of ADD. The rate at which the brain uses glucose, its main energy source, was shown to be lower in persons with $\mathrm{ADD}$, especially in the portion of the brain that is responsible for atten- 
tion, handwriting, motor control, and inhibition responses. ADD can also be described as a set of attributes that typify the ADDer's life. The National ADDA Factsheet (Jaska, 1998) indicates that the most common core features include distractibility (poor sustained attention to tasks), impulsivity (impaired impulse control and delay of gratification), and hyperactivity (excessive activity and physical restlessness).

In a more positive light, some researchers draw a parallel between ADD and hunter-entrepreneur traits that include constant environmental monitoring, visual thinking, independence, enjoyment of new ideas and excitement, and willingness to take risks, but also frequent boredom (Harrell, 1994). Experts cite examples such as Albert Einstein, Benjamin Franklin, and Christopher Columbus, who are thought to have had ADD (Ukens, 1995).

In order to better understand consumer impulsivity as an ongoing trait in life experiences, several ADD support groups and experts were contacted by the authors and asked to provide comprehensive background and suggestions for this investigation. Based on their input, a semistructured survey was utilized to elicit first-person descriptions of shopping experiences from individuals with ADD. The manuscript presents an analysis of their stories in order to further build an understanding of consumer impulsivity.

\section{BACKGROUND}

\section{Impulsivity}

Consumer researchers have studied impulsive behavior over several decades, with definitions often limiting their focus to characteristics such as irresponsibility, immaturity, and carelessness, rather than also including impulse purchases that take advantage of an unforeseen opportunity (Rook \& Fisher, 1995). Running counter to more extended information-processing approaches, impulsive buying is highly spontaneous, reactive, unplanned, and frequently linked with producing unsatisfactory choices, providing a somewhat negative bias.

Recent investigations have suggested that impulsivity is more complex than previously described, being affected by variables including situational factors, marketing stimuli, characteristics of the individual, and other linked behaviors that can interact with an impulsive urge to buy. For instance, Rook and Fisher (1995) propose that the probability of individuals making impulsive purchases depends on two things: (a) the degree to which they possess impulsive trait tendencies and (b) their normative judgments that may allow or prevent such purchases (p. 305). Their studies provided evidence that the impulse to buy may be moderated by the individual's evaluation of whether the target purchase is appropriate and acceptable, given any circumstances that they are experiencing. 
Similarly, Beatty and Ferrell (1998) criticized traditional definitions of impulse buying as "unplanned purchasing" as being inadequate and limited. In order to provide a more precise definition, they also incorporated into their definition that the individual had "no pre-shopping intentions to buy a specific product category or to fulfill a specific buying task" (p. 170). Their actual shopping data supported their contention that impulse buying is directly influenced by situational variables (time available and money available) and by individual difference variables (shopping enjoyment and impulse-buying tendency). Additionally, impulse buying is moderated by positive and negative affect, increased in-store browsing, and the felt urge to buy impulsively (Beatty \& Ferrell, 1998).

Finally, impulse buying was broadened to the more inclusive notion of "consumption impulse," allowing for the consideration of impulsive product purchase, use, or disposal (Dholakia, 2000). Similar to the preceding conceptualizations, consumption impulse occurs without reflection and is spur-of-the-moment, but may be triggered by in-store marketing stimuli, situational factors affecting the individual, such as mood, as well as the level of the impulsivity trait possessed by the individual. Dholakia suggests that acting on a consumption impulse is not automatic, but instead is moderated by constraining factors that may stimulate cognitive evaluation, leading to resistance of the irresistible urge to make a purchase.

Following Dholakia (2000), it is likely that consumer impulsivity may involve a variety of aspects of consumer behavior that exist both within and apart from the buying situation. Informal interviews with ADDers seemed to suggest that the concept was much more complex than making unplanned purchases in the store setting. Their comments implied that unplanned attractions to in-store displays, information overload from intense in-store stimuli, and inability to find desired products may also be related to impulsivity. The literature on attention deficit disorder offers support that similar problems with distractibility exist in school and work settings.

\section{Prevalence of Attention Deficit Disorder}

To the extent that ADDers experience impulsivity in their consumption behavior, such behavior may be present in a large portion of the U.S. adult population. Although previously thought to be a childhood condition that can be outgrown, Barkley (1998) indicates that 50-70\%, and Murphy (1992) found that 30-70\%, of children with ADD continue to have symptoms such as inattention, impulsivity, and motor activity into adulthood. Furthermore, Biederman et al. (1994) note that four types of studies (clinically referred adults; longitudinal studies; family-genetic studies; and psychopharmacological studies) indicate that $\mathrm{ADHD}$ continues into adulthood. Experts suggest 2-5 million (4-6\% of the U.S. population) as a conservative estimate of the number of U.S. adults with ADD. 


\section{The Gender Controversy}

$\mathrm{ADD}$ is reported to be more likely to affect males than females (with a typical ratio of boys outnumbering girls by 3 to 1 ), but experts report that the gender breakdown of ADD is controversial (Nadeau, Littman, \& Quinn, 1999). A series of studies in Additudemag.com, an on-line publication, explained that the discrepancy is due to the level of diagnosis of boys versus girls. Some experts estimate that up to $75 \%$ of females with ADD may be missed. According to Dr. Peter Jaska (1996), although it is often reported that "males are 2 to 3 times more likely to be diagnosed than females," this is because females are more likely to have ADD without hyperactivity (FAQs on ADD, 2003; Solden, 1995). As a result, boys with $\mathrm{ADD} / \mathrm{ADHD}$ tend to act out, show aggression, and engage in disruptive behavior (Solden, 1995). The visible disruptive behavior can easily be documented, leading boys to be diagnosed more frequently (Gershon, 2002; Jaska, 1996; Solden, 1995). Gershon (2002) also observes that general disruptive behavior may cause ADD to be overdiagnosed in boys.

Girls, on the other hand, tend to withdraw and may be characterized as daydreamers. They are often seen as having cognitive and learning problems, instead of ADD. Because their behaviors are not disruptive, they may not be diagnosed until they are adults, when they may also suffer from anxiety and depression (K. Nadeau, personal communication, 1999). Even then, women who have ADD/ADHD may be misdiagnosed as disorganized or suffering from depression (Solden, 1995). In fact, it has been argued that male ADD/ADHD symptoms have been used to create standards of diagnosis that are not necessarily appropriate for all females (K. Nadeau, personal communication, 1999), further prolonging the gender bias (Crawford, 2003). Often women do not recognize that they have ADD themselves until their child(ren) is diagnosed (Solden, 1995).

A study of gender differences in adult ADHDers found that males and females had similar impairments in cognition and were more impaired than the control groups (Biederman et al., 1994). Although Biederman et al. (1994) also found that females had lower rates of conduct disorder than males, females also had higher rates of conduct disorder than control-group adult females. Walliser (1999) suggests that "experts suspect that future ADD demographics probably really reflect the gender split of the general population." Gershon (2002) proposes that more females are needed in ADHD studies.

\section{Diagnosis and Treatment}

Perhaps the most exhaustive literature regarding diagnosis centers on ADD in educational settings (see Atkins \& Pelham, 1991, for a thorough review of school-based assessment methods). Numerous scales have been developed that allow for teachers to rate their students on various ADD/ADHD related symptoms. These can be accompanied by peer rat- 
ings by children of their classmates and direct observation by professionals. Although child study teams typically diagnose ADD identified through classroom behavioral symptoms, adults may not learn about their ADD until they have experienced career, financial, and personal difficulties (Hallowell \& Ratey, 1994; Murphy, 1992) that bring them to professional treatment (Wolkenberg, 1986).

Attention deficit disorder may mimic or coexist with other types of learning disorders, such as reading disabilities (Dykman \& Ackerman, 1991), anxiety disorders, mood disorders, and other medical conditions (Rostain, 1988). In addition, ADDers may experience fine motor disorders, such as illegible handwriting as well as other learning disorders related to information processing (Melini, 1987). Several of these disorders can contribute to consumption impulsivity.

Treatment for ADD often includes the prescription of psychostimulants such as Ritalin for the management of ADD-related symptoms in children, adolescents, and adults. Such medications often have a calming effect, and thus help decrease impulsivity and hyperactivity, increase attention, and may decrease aggression (Melini, 1987; Young, 1999). Although treatments have largely focused on the effects of stimulant medication (Young, 1999), many researchers propose that the most effective treatment for ADD includes a combination of medications, therapy, or counseling to learn coping skills and adaptive behaviors, and ADD coaching for adults (Jaska, 1998). Behavioral therapy attempts to identify and maximize the individual's strengths, while teaching them to control or compensate for their limitations.

\section{CONSUMER IMPULSIVITY AND PERSONS WITH ADD}

\section{Information-Processing Problems as a Precursor to Consumer Impulsivity}

Schroder, Driver, and Streufert (1967) point out that the same information can be processed different ways. For those whose informationprocessing structure is concrete, once a stimulus is categorized, it tends to stay in that category. New information is distorted or ignored, so as not to upset the categorization already in place. For those with more abstract structures, there are more alternative conclusions generated. Decisions are made on the basis of more information, but the categorization is less fixed. The person is willing to look at the information in different ways, and therefore may change conclusions and attitudes. Such a system has a high integration index compared with concrete structures.

One might hypothesize that those with ADD have abstract information processing structures. This is because persons with ADD appear to 
pay attention to many more cues than the average person (Hallowell \& Ratey, 1994). In addition, ADDers may be able to process information using more abstract structures because they more easily find connections between concepts and therefore can generate more alternatives (Hallowell \& Ratey, 1994).

In spite of this latent ability, such abstract information-processing structures are not likely to be realized. The first step in information processing is to categorize stimuli (Schroder et al., 1967). Research indicates that ADDers have problems encoding and retrieving information (Holdnack et al., 1995; Melini, 1987; Woods, Lovejoy, \& Ball, 2002). Solden (1995) relates the problem of encoding to lack of organization skills. Nadeau (1995) suggests that successful encoding may not occur because of the high distractibility of ADDers. They may not be paying attention to the information in the first place, and thus do not have the information to encode. Melini (1987) notes ADDers are unable to process information in a series or order; this is true even when the information is provided in an organized manner, for example, following multiple-step instructions. Less information may be acquired and usefully processed as a result. In fact, research by Holdnack et al. (1995) shows that adult $\mathrm{ADDers}$ acquired less information than non-ADD adults. ADDers process information more slowly (Holdnack et al., 1995) than non-ADD adults.

Problems with highly integrated information processing does not mean that ADDers can therefore successfully revert to concrete structures of information processing, because the same basic functions of attention and organization are required. Attention is compromised because ADDers have problems with visual-spatial disorders, leading some to have trouble distinguishing background from foreground (Melini, 1987). In general people with ADD have trouble determining which information to attend to and which to screen out (Solden, 1995). Thus, they cannot simply ignore information that does not fit their fixed perceptual categories.

When the information-processing structure is highly integrated, it can handle more diversity, better discriminate between stimuli, and generate more alternatives. Up to a certain point, more information results in a greater number of decisions being made. However, when there is information overload in the environment, the informationprocessing structure becomes less abstract and more concrete. As this happens, the quality of the output eventually declines. Although the number of decisions may increase, "they are now immediate responses to isolated stimuli" (Schroder et al., 1967, p. 99). Such isolated stimuli may be randomly selected by the ADDer (Goodwin \& Corgiat, 1992). Alternatively, the ADDer may focus on nothing (Nadeau, 1995). Because ADDers tend to look holistically at stimuli, rather than prioritize and focus on the most important subsets (Solden, 1995), they are more likely to experience information overload when exposed to a stimulus environment that a non-ADDer could successfully deal with. 


\section{Information Overload and Consumer Behavior}

Several studies examined the relationship between information overload and quality of decision making specifically in consumer behavior (including Jacoby, Speller, \& Kohn, 1974a, 1974b). Whether more information results in better decision making has been debated (Malhotra, Jain, \& Lagakos, 1982). Although these studies offer valuable insights into information overload and consumer decision making, they shed little light on the issue of impulsive consumer behavior. This is because in these studies consumers are forced to make a choice between brands that are presented to them. In the case of impulsive consumer behavior, in contrast, the consumer is in the "real world." The consumer has the option of simply buying a product that was not included in the original shopping plan, of not buying the product that was included, or of simply buying nothing, although the shopping trip was made with the intention of making purchases.

\section{EXPECTATIONS OF THE CONSUMER EXPERIENCES OF PERSONS WITH ADD/ADHD}

As noted above, ADDers have problems with information retrieval. Research shows they have deficiencies in both visual and auditory-verbal memory tasks (Woods, Lovejoy, \& Ball, 2002). Nadeau (1995) suggests that if a person has not successfully encoded information to begin with, there will be no information to retrieve from memory. Nadeau (1995) also notes that ADDers have significant problems with prospective memory, that is, remembering to remember.

Based on these clinical descriptions, the authors anticipated that ADDers would experience a lifetime of difficulty with product use and shopping behaviors, especially those that involve visual-spatial, language, fine motor, sequencing, and memory tasks in information processing. These expectations are summarized in Table 1.

Distractions. Figure-ground issues may create problems, for instance, when reading directions. Small print may go unnoticed, especially if prominent logos and slogans also appear on product packages, resulting in impulsive use of products before directions are understood. When in retail stores, other marketing stimuli and situational factors such as displays, colors, and lights may pull attention to the point of distraction. These antecedents are expected to distract the ADD consumer from their original purpose and potentially attract them to other, unintended items in the retail store setting. In both cases, consumption impulses are expected to be formed and potentially enacted. However, a more complex set of linkages than those proposed by Dholakia (2000) are likely because of the intricate makeup of ADD. Because ADD customers may be overloaded with alternative stimuli, cognitive evaluation and/or self- 
Table 1. Expected Consumer Experiences of Persons with ADD/ADHD.

\begin{tabular}{|c|c|}
\hline ADD Characteristics & $\begin{array}{c}\text { Anticipated Consumption Impulsivity } \\
\text { Outcomes }\end{array}$ \\
\hline $\begin{array}{l}\text { May mimic or co-exist with other types of } \\
\text { learning disorders, such as reading } \\
\text { disabilities (Dykman \& Ackerman, 1991) }\end{array}$ & $\begin{array}{l}\text { Small print may not be noticed; text may be } \\
\text { misunderstood; frustration with reading } \\
\text { may be reported. }\end{array}$ \\
\hline $\begin{array}{l}\text { May mimic or co-exist with anxiety } \\
\text { disorders, mood disorders, and other } \\
\text { medical conditions (Rostain, 1988). }\end{array}$ & $\begin{array}{l}\text { May report frustration and feelings of } \\
\text { failure; may act to reduce perceived tension. }\end{array}$ \\
\hline $\begin{array}{l}\text { Visual-spatial disorders, in which some } \\
\text { have trouble distinguishing background } \\
\text { from foreground (Melini, 1987) }\end{array}$ & $\begin{array}{l}\text { May not be able to distinguish central from } \\
\text { peripheral information; may fail to find } \\
\text { needed information about products, such as } \\
\text { prices and sizes }\end{array}$ \\
\hline $\begin{array}{l}\text { Difficulty in interpretation of verbal } \\
\text { instructions (Melini, 1987) }\end{array}$ & $\begin{array}{l}\text { Difficulties with product directions and } \\
\text { assembly; signs in stores may not convey } \\
\text { needed information }\end{array}$ \\
\hline $\begin{array}{l}\text { Fine motor disorders, such as illegible } \\
\text { handwriting (Melini, 1987; Nadeau, 1999) }\end{array}$ & Inability to decipher shopping lists \\
\hline $\begin{array}{l}\text { Inability to process information in a series } \\
\text { or order, following multiple-step } \\
\text { instructions (Melini, 1987) }\end{array}$ & $\begin{array}{l}\text { Experiencing "too many" stimuli as } \\
\text { consumers; having difficulty telling stimuli } \\
\text { apart; can lead to difficulty with product } \\
\text { assembly }\end{array}$ \\
\hline $\begin{array}{l}\text { Inability to retrieve information that they } \\
\text { have gathered which is specific, such as a } \\
\text { recalling particular fact on an } \\
\text { examination (Melini, 1987) }\end{array}$ & $\begin{array}{l}\text { Forgetting what they came to store to get, } \\
\text { particular product attributes, brands }\end{array}$ \\
\hline $\begin{array}{l}\text { Intake of multiple stimuli (Hallowell \& } \\
\text { Ratey, 1994); problems with encoding and } \\
\text { retrieving information (Woods, Lovejoy \& } \\
\text { Ball, 2002) }\end{array}$ & $\begin{array}{l}\text { Inability to encode information usefully; } \\
\text { difficulty categorizing information; can lead } \\
\text { to impulsive purchase of undesirable item, } \\
\text { lack of purchase intended items }\end{array}$ \\
\hline $\begin{array}{l}\text { Trouble selecting relevant information/ } \\
\text { screening out information (Solden, 1995) }\end{array}$ & $\begin{array}{l}\text { Situational factors such as displays, colors, } \\
\text { and lights may pull attention to the point of } \\
\text { distraction }\end{array}$ \\
\hline $\begin{array}{l}\text { More likely to experience information } \\
\text { overload (Solden, 1995) }\end{array}$ & $\begin{array}{l}\text { Difficulty processing in-store information, } \\
\text { retrieval of memory }\end{array}$ \\
\hline $\begin{array}{l}\text { Speed of processing and verbal learning } \\
\text { deficits of persons with ADD. Holdnack, } \\
\text { Moberg, Arnold, Gur, et al. (1995) recall } \\
\text { inconsistency, slowed cognitive processing, } \\
\text { and a significant list-learning deficit }\end{array}$ & $\begin{array}{l}\text { Less information is recalled, acquired, or } \\
\text { processed, impulsive purchases are likely to } \\
\text { be made based on incomplete information, } \\
\text { frustration, and inability to retrieve needed } \\
\text { product information. }\end{array}$ \\
\hline
\end{tabular}

control may be blocked even when constraints to enactment occur. Such constraints may include not having enough money to make an impulsive purchase; the desire to avoid specific consequences of buying the product, such as increasing debt; or wanting to avoid negative emotions. However, the attractiveness of in-store stimuli may be too strong to resist, resulting in distraction by in-store displays and purchases of unintended products. 
Faulty Information Processing. Given that less information is acquired, processed in an organized manner, or recalled, impulsive purchases are likely to be made based on incomplete information, frustration, and inability to retrieve needed product information. When information overload occurs, people may make hasty responses to isolated stimuli, as Schroder et al. (1967) indicate. One type of hasty response can be impulse purchases. Although such decline in information processing is not ADD-specific, ADDers are likely to reach the informationoverload stage more quickly than others. Because of the numerous information-processing problems described above, ADDers' behavior may be impulsive in nature, but derive from faulty information processing and the frustration often experienced by persons with $\mathrm{ADD}$.

Based on the general traits of persons with $\mathrm{ADD}$, it is expected that ADDers will report impulse purchasing as a long-term characteristic of their consumer behavior. In addition, other problems with overall consumer management behaviors can be expected to contribute to their tendency toward impulsivity. These include problems of experiencing too many stimuli, experiencing figure-ground reversal and impulsively reacting to peripheral cues, having difficulty telling stimuli apart, becoming distracted from their original shopping purposes, forgetting specific product aspects such as brands or sizes, and having difficulty with product assembly.

\section{METHODOLOGY}

The purpose of the article is to capture the ADDers' experiences as consumers in order to broaden the understanding of consumption impulsivity and to develop a framework for further investigation. Each ADDer was asked to scroll backward through his/her inventory of consumer experiences, guided by an informal list of issues to prompt his or her responses. Closed-ended questions were interspersed with open-ended questions that asked the respondents to provide examples of relevant marketplace experiences. The list was deliberately general in nature, asking for experiences while shopping, using products, and viewing advertising. If problems were reported, the respondents were asked to describe the situations in which the problems occurred. This loosely structured approach allowed each respondent to elaborate upon his or her experiences vividly and freely for use in the analysis.

Two samples provided responses in the study: (a) professionals who diagnose, counsel, and treat persons with ADD/ADHD; and (b) adults with $\mathrm{ADD} / \mathrm{ADHD}$. In order to hone this approach, a sample of experts was initially contacted for input and advice. Nineteen experts were identified from several ADD Web sites, support groups, and lists of practicing clinicians. They were contacted by the first author, with an explanation of the study goals and a request for input regarding their experience 
with ADDers as consumers, suggestions for sampling, and recommended research methods. They were asked to comment on the semistructured survey developed for use with ADDers. Seven of the contacted experts responded, providing summaries of their clinical experience, publications that addressed issues in this study, and advice regarding Web recruitment of respondents with ADD. In addition, five other experts have provided advice during the latter phases of the study, offering insights and ongoing advice on sample characteristics.

With the use of input from the ADD experts, the survey was made available to the second group, consisting of persons with ADD/ADHD. Respondents for this sample were recruited with the use of several avenues:

1. The ADD experts identified persons to receive the survey.

2. Several on-line ADD support groups were contacted and recruited participants.

3. The survey was also posted on the Web site of one of the authors, and notification was sent to various support groups for persons with ADD, such as CHADD groups and support Web sites.

The respondents were encouraged to respond by telling personal stories of product and shopping experiences while speaking in their own voices, with their own feelings, problems, and frustrations.

A total of 62 persons ${ }^{1}$ with ADD/ADHD responded to the survey through one of the three methods. There were 46 women and 16 men. Fifty were employed in a variety of careers, 10 were students, and 2 were unemployed. Their careers included management, retailing, nursing, optician, private investigator, engineer, computer specialist, teacher, and a wide variety of others. Their ages ranged from 21 to 59, with an average age of 37.9 years. By researching this attribute-specific group, it was hoped that the multidimensional nature of the impulsivity construct would be revealed.

\section{THE ADD EXPERTS SAMPLE}

An interesting picture emerged from the ADD experts. They responded in several formats, including personal communications, references to various books and/or Web sites that they had published, and telephone calls. They verified that there is a dearth of academic research on ADD and consumer behavior and agreed with its importance in their counseling work. They emphasized that many ADDers discussed their frus-

\footnotetext{
1 The data were collected from the ADD/ADHD adults at two separate intervals. The KolmogorovSmirnov two-population test did not reveal any significant differences between the two waves, so they were pooled.
} 
trations with retail shopping in support-group contexts, but there is little published research that documents this to be true across samples of ADDers. They shared consumer-related counseling problems they had encountered, expectations from their knowledge of typical ADD characteristics, and suggestions for methodology. Two experts recommended specific publications of their own that they felt were relevant to the study. Both their comments and their publications are used in summarizing the experts' point of view.

In addition, the experts suggested that female ADDers were more likely to respond to a consumer survey because they were (a) more accepting of their diagnosis than men, (b) more likely to seek help with ADDrelated problems, and (c) more likely to respond to a survey discussing consumer issues (L. Kinkaid, Coordinator, CHADD of Burlington CountySouth Jersey, personal communication, 2003; R. Monahan, personal communication, 2003). However, because " $[t]$ he generally accepted estimate of women's buying power puts it at 80 percent of all household spending" (Barletta, 2003, p. 6), it was felt that their greater representation in the sample helped to better reflect the population of interest (i.e., shoppers).

\section{Impulsivity as a Lifetime Experience}

Based on their experiences with ADDers in their own clinical practices, several of the experts hypothesized that problems would result from the ADDer's impulsive nature and problems with information processing (T. Matlen, personal communication, 1999; L. McFeeters, personal communication, 1999; K. Nadeau, personal communication, 1999). They expected that ADDers would purchase without thinking, yet fail to obtain planned purchases, because ADDers indicate feeling overwhelmed by choices and by complex shopping environments, such as malls. They suggested that overstimulation in stores and in malls might pull the ADDer's attention away from the task at hand, causing them to become flustered and irritated. According to personal communication from Dr. Kathleen Nadeau, a noted expert on ADD studies, there are several common consumer problems of persons with ADD: (a) impulse purchases constitute a major problem for those with ADD; (b) memory problems enter in as wellpurchasing, repeatedly, items that one has one of at home because one has forgotten, for example, four jars of mayonnaise; (c) never filling out and/or losing warranty information, because paperwork is a major problem for most with ADD; (d) never getting around to returning unwanted items; (e) purchasing on-line or by catalog, but never returning unsuitable items because it takes too much organization to do so; (f) going shopping for a particular purpose, but easily getting distracted, as when one man went to the store for milk and came home with a kayak; and $(\mathrm{g})$ feeling overwhelmed in large groceries, department stores, and shopping malls because of overstimulation, sensitivity to light, sound, and so forth. 
Romaniuk (1996) examined "impulsive spending and money management problems in ADD adults." The definition of impulsive spending incorporated many consumer problems: "sudden, spontaneous purchasing ... based on an urge rather than calculated thought; frivolous, capricious, or nonessential; highly similar to or duplicate of things already owned." The author drew his data from his individual and group clinical work with ADD adults in the effort to offer advice and strategies to help his clients deal with financial problems. Examples included purchasing an item even though several are owned, supplies for projects that are never started or completed, and items that are rarely used. Romaniuk argued that ADDers have a greater vulnerability to spend, reacting to highly stimulating visual advertising claims, appeals to psychological needs, and inducements to act immediately. The notions of instant credit, time-limited discounts, and immediate results were found to appeal to the ADDers' needs for immediate gratification. All of these traits would be expected to increase the amount of impulsive buying.

\section{TELLING THEIR STORY-THE SAMPLE OF ADDers}

\section{What Does ADD Mean to an ADDer?}

In order to obtain a general idea of what the ADD experience was like, the survey asked the respondents to first describe their ADD in their own words. They gave a mix of clinical, medical, educational, and personal information that created a picture of a topsy-turvy world with intense perceptions, distractions, confusions, and memory issues that defined their everyday lives. They emphasized their high intelligence, yet likelihood of encountering problems with family, friends, and job loss. The difficulties interpreting numerous stimulus inputs was a common theme, especially sounds, movement, touching, crowdedness, and fluorescent lighting:

I live in a constant scrambling of thoughts with several impulses that bring me quickly from the start of one thing to the midst of another to another ... I relate things that seemingly have no relation, but make sense to me ... My emotions are extreme and change quickly. (Jennifer, 30)

$\mathrm{ADD}$ is a neurological disorder which causes many symptoms including inattentiveness, hyperactivity, forgetfulness, difficulty with organizational skills, distortion of time perception, impulsivity, and the poor attention to detail which manifest in the ADDers life by disorganization, chronic lateness, messy, cluttered homes and workplaces, problems maintaining relationships and difficulty maintaining employment. (Rachel, 48) 
A problem filtering information and stimuli which causes you to be more apt to react to distractions by losing track of the task at hand. (Kathy, 33)

These respondents included impulsivity as a basic trait of ADD. Eightyseven percent gave descriptions including at least one of the following characteristics: an inability to focus, lack of concentration, hyperactivity, constant distractibility, or impatience.

\section{Similarities of Consumer Experiences across Respondents}

In order to determine whether there was a similar pattern of consumer experiences across respondents, each person was asked to respond to a set of closed-ended questions. A tabulation of their responses is given in Table 2. For instance, the findings indicated that $90.3 \%$ of those responding reported buying many products on impulse. Moreover, $79.0 \%$ of those responding were drawn to look at other products when they passed them in stores. The ADDers reported that they attempted to use consumer information, but about half had problems in processing that information, such as following directions and using in-store information.

However, indicators such as these did not provide insight into the specific nature of the experiences, such as whether certain types of

Table 2. Responses to Consumption Impulsivity Closed-end Questions.

\begin{tabular}{|c|c|c|}
\hline Variables & \multicolumn{2}{|c|}{$\begin{array}{l}\text { Percent Agreeing or } \\
\text { Strongly Agreeing }\end{array}$} \\
\hline Ra & $\mathrm{w}$ percent 1 & Corrected percent \\
\hline \multirow{2}{*}{\multicolumn{3}{|c|}{$\begin{array}{l}\text { Had a problem with products you buy } \\
\text { Problems following directions or with }\end{array}$}} \\
\hline & & \\
\hline \multicolumn{3}{|l|}{ Problems understanding messages in } \\
\hline Problems when shopping & $71.0 \%$ & $74.6 \%(n=44 / 59)$ \\
\hline Buy many products on impulse & $90.3 \%$ & $91.8 \%(n=56 / 61)$ \\
\hline Accomplish all set out to do while shopping & $35.5 \%$ & $37.3 \%(n=22 / 59)$ \\
\hline Follow a list when shop & $51.5 \%$ & $53.3 \%(n=32 / 60)$ \\
\hline Become confused by information in stores & $48.4 \%$ & $50.0 \%(n=30 / 60)$ \\
\hline Read labels before buy products & $50.0 \%$ & $52.5 \%(n=31 / 59)$ \\
\hline & Drawn to look at other products when & $81.7 \%(n=49 / 60)$ \\
\hline Get all planned shopping done on trip & $30.7 \%$ & $31.7 \%(n=19 / 60)$ \\
\hline Shopping frustrates me & $56.5 \%$ & $58.3 \%(n=35 / 60)$ \\
\hline \multicolumn{3}{|l|}{ Sometimes hard to find products } \\
\hline looking for & $61.3 \%$ & $64.4 \%(n=38 / 59)$ \\
\hline
\end{tabular}

Note. The raw percentages are computed on the total sample of 62 persons. The corrected percentages are given in terms of the number of individuals who actually responded to each question. 
products were bought impulsively, whether lists were used productively, or whether particular types of stimuli were distracting to ADDers. The respondents were provided the opportunity to give illustrations in the open-ended questions listed in Table 3. Because the questions were open-ended, and because ADDers might find it difficult to respond in depth to open-ended questions, the study was not likely to receive high numbers of responses dealing with each specific issue. In fact, because the questions were general, it was notable to find several people identifying a common set of problems. Overall, the specific issues identified revealed a variety of information-processing problems. Note that the open-ended questions were less straightforward to quantify, because some respondents did not answer all of them, some responded to one question while answering another, and other respondents provided multiple responses. For clarity, the number of persons whose responses represent common issues or themes regarding their consumer experiences is given in parentheses.

The combination of both types of data help to describe consumption impulsivity in the context of numerous shopping experiences that reflect underlying complex information processing and attempts at deliberate information control.

Table 3. Open-ended Questions.

Could you describe your ADD in your own words?

Do you have problems following directions or assembling products? If yes, could you give an example?

What could companies do to help you with the type of problem that you described?

Could you describe a problem with advertising that is typical for you?

What could companies do to help you with the type of problem that you described?

Problem while shopping: Could you describe the type of situation when this type of problem happens?

Could you describe a shopping problem that is typical for you?

What could companies do to help you with the type of problem that you described?

Do you find that you buy many products on impulse? If so, could you give an example?

How would you describe your ability to find what you are looking for in stores?

If you have difficulties, when do they occur?

If you could speak to the Marketing Industry today, what would you want them to know about consumers with ADD? 


\section{Conceptual Ordering as a First Step in Explanation}

The open-ended responses were read and reread to determine whether any patterns existed in the events, objects, and themes in their stories, following the approaches found in grounded theory development (Miles \& Huberman, 1994; Strauss \& Corbin, 1998). Responses were summarized by recoding them into key phrases for each major idea offered by a respondent. These key phrases were input into an Excel spreadsheet so that similar responses could be examined, sorted, and counted for their frequencies of occurrence. The authors looked for themes relating to information processing, distractibility, impulsiveness, as well as purposive thinking, list making, and orderly use of products. As data collection progressed, similar themes began to emerge. This process, termed conceptual ordering by Strauss and Corbin (1998), allowed for systematic examination of the responses in extracting common properties, concerns, and dimensions used in the language of ADD reality. Interestingly, a blend of deliberate and impulsive themes emerged, as many respondents were actively seeking to manage their impulsivity and reduce distractibility in the retail environment. Data collection was terminated when new information did not appear in the responses and the investigative categories were saturated (Strauss \& Corbin, 1998, p. 212). Because confidentiality had been promised, all persons were assigned a pseudonym. Their code names and their ages are given in parentheses following each statement in order to identify quotations from specific individuals. In order to capture the voices and feelings of each respondent (Stern, 1998), the quotations are presented exactly as given, with slang, misspellings, and added emphasis in capitals.

\section{Intelligence plus Confidence plus Simple Consumer Mistakes}

A common theme that surfaced was the ADDer's frustration with being intelligent, perhaps more intelligent than others, yet being characterized as someone who was impulsive, distractible, and disorganized. They were acutely aware of their consumer-related problems and their relationship to ADD. They felt that they had been stigmatized by their families and by the educational system as failures who simply needed to pay attention and work harder. The respondents were disappointed in themselves and often frustrated by the seemingly small steps that eluded them again and again, whereas some reported improvements in impulse control:

When I give in to impulse purchases, I often return the product or keep and or not use it. Generally, impulse purchases are disappointing. So I find impulse marketing counter-productive. I'm pretty good about not buying on impulse any more. (Sally, 40)

I've learned to compensate for my ADHD by having a master shopping list that I just print out from my computer and hi-light the items to 
purchase. My problems come from the store re-arranging things, long lines, inability to track down assistance when needed, interruptions (i.e. cell phone call), spacing out, etc. I no longer enjoy shopping for the pure joy of it and purchase a lot online now. I settle for clothes from Costco or Walmart b/c I know I can do almost all of my shopping in one place. (Ida, 53)

When it gets complicated I give up, or ask my daughter to help. I often avoid the situation all together and go without, or wait for a good day when I think I can cope with a little frustration. I have been known to call friends on my mobile in shops for clarifircation if I do not understand something. (Melissa, 48)

\section{Dysfunctional Consumer Behavior-The Result of Frustration}

The respondents clearly indicated patterns of frustration in buying unneeded products and never using some purchases. In fact, many respondents gave multiple reactions to the study questions. They indicated several reasons why problems in shopping occurred. Several common themes were found, such as (a) experiencing difficulties with decisions, choices, and comparisons (19 respondents); (b) inability to find items, locating wrong items, and getting lost (18 respondents); and (c) being overwhelmed or distracted by audio, visual, or other stimuli (18 respondents). Others indicated that unfamiliar or disorganized stores "caused" their problems to occur. When they do, the ADDers reported being aware that they were taking too long to accomplish what they set out to do. They reported wandering aimlessly in stores or going back and forth from department to department in the effort to find what they came to purchase.

Inability to Make Decisions. Typical consumer decisions, such as making comparisons, finding the best product, using price information, and making choices among products, were difficult and frustrating for ADDers. When asked to describe their typical shopping problems, the respondents provided several illustrations. They reported having too many things to choose from (Laura, 53), forgetting or not using their lists (Monica, 33), and giving up when it gets complicated (Melissa, 48). Some reported not even trying to evaluate products before purchase:

I just went and bought a new dishwasher last night! I often buy things without trying them on first (clothing), and then decide when I get home that I shouldn't have spent the money, didn't like the product, or didn't even need the product. (Lynn, 27)

Overwhelming Environments. ADDers felt that store environments worked against them by presenting distractions to effective shopping, heightening the effects of their ADD. Many common attributes that retailers build into their servicescapes were actually assessed as annoyances 
and distractions, such as rearrangements of products, background audio systems, specific types of lighting, and giving free samples in areas where the product is not located for purchase. Many reported that providing multiple brands and sizes increased the likelihood of making bad consumer decisions, impulsive and unnecessary purchases, and incomplete shopping trips.

I have a hard time choosing what kind of clothes to even try on. There is such a large selection, I walk around aimlessly and usually never end up buying what I was originally looking for. Most of the items I buy are on impulse. They tend to be large items such as televisions, computers, stereos, home theatre systems. I haven't bought new clothes in two years. Sometimes I have to make a list of the things I need to buy, but then I forget the list and wander through each of the aisles until I see something that triggers me to remember the product I need to buy. (Michael, no age given)

Sometimes in stores I may be going in for one thing, but instead of going right where I need to go i.e. the dairy section for milk, I will wander aimlessly throughout the supermarket seemingly mesmerized by all the products, lights, people, etc. (Beth, 32)

Various types of background noises or product demonstrations were reported to add to the confusion of shopping situations. Although many electronics retailers attempt to provide walls of televisions, computers, and video products, the amount and intensity of such stimuli apparently created an environment that actually interfered with product evaluation, confusing the ADDer with too much stimulation and too much input to be useful:

Fluorescent lighting in the stores overwhelms me ... I am unable to make clear, rapid purchasing decisions and just end up wandering through the aisles looking at everything that catches my attention. (Ida, 53)

Can't find what I want-product or category. Stores are confusing. Can't easily winnow out product attributes to comparison-shop. Too many messages. Too much sensory input. Loud sounds are especially hard for me. I can't shop in electronics stores, for instance, the din is awful and distracting. I can't focus on the products because of the distracting noise. (Sally, 40)

Some of the respondents hated shopping and linked that feeling with their impulse purchases. In other words, their impulse to buy was not toward a particular desired object, but instead was aimed at making immediate purchases so that the shopping experience would be finished. 
This particularly occurred when stores were perceived as disorganized or if products had been moved from their regular place.

Stores that are very unorganized are very overwhelming, and due to the fact that the mind of an ADD individual is "all over the place" if something is hard to find or not visible it's easier to grab the next best thing or something completely different. However with ADD you tend to be very brand loyal, there is enough chaos in the mind, so establishing a brand identity gives one "order." (Sandy, 26)

I'm too impatient to do a laborious search if I can't find what I'm looking for right away... so my mind wanders to something I see and think I might need. Ultimately, I find something of interest along the way. Something I don't really need but will justify my trip. (Andrea, 46)

\section{IN-STORE FRUSTRATIONS LEAD TO IMPULSIVE NONPURCHASING AND INCORRECT PURCHASES}

Shopping appeared to be a pattern of predictable forgotten needs, forgotten lists, and forgotten brands. The respondents echoed their frustration with the repetition of such problems and ached for memorable packages and brand names that enabled them to fulfill their purchases despite lacking the information that they often were unable to retrieve.

I go into a supermarket to buy light bulbs ( 3 weeks in a row now), get allsorts of stuff, bargains galore, not one flippin light bulb, in 3 weeks and over 5 trips to the shops to buy light bulbs, i now have 3 rooms in the house with no light bulbs. (Megan, 30)

For some, brand names were not readily retrievable and logos were not memorable, leading the respondents to report that they made the same consumer decisions over and over in great frustration. When one's shopping goals are forgotten, it was common to purchase other things that happened to be seen. Thus, impulse purchases might actually result from forgotten goals.

I can't remember simple things like do i buy Heinz or Hunt's ketchup . .. every time I go it is ... like the first time and I have to make a lot of decisions all over again. In shopping for things other than groceries, I try to comparison shop and remember things I have read but often end up frustrated and just go for the best price. I am very impulsive and will often pick up any new product that catches my eye. (Rachel, 48)

... almost every time i forget the list of things needed. Then I have to work off my memory which isn't bad, but the asiles are confusing to me and i end up going to get milk and have to go to the other side of the store 
to get pop. then back over to the bread section were i had just left, when i got the milk! and turn around, back to the front of the store to get a shopping cart passing the magazine section, and seeing something interesting out of the side of my eye stopping and flipping through a mag or two i then put it down and go to the registers to check out. Get home and my wife is breathing flames because It was a 15min run to the store turned into $45 \mathrm{~min}$. I purchased a magizine and didn't get the eggs that were on the list. Thats almost every time i go to the store. I don't have a choice in this matter I can't control it! before i go into a store i tell myself i'm just running in real quick, and it turns out like i discribed above. I don't even realize it until i get into the car. I hate this disability. When I discribe that to people they respond, "just stop doing that." How can you stop it when you can't control it. (Edward, 32)

Consumers generally want to have considerable choice and selection variety. However, the sample ADDers reported that the sheer amount of in-store choice overwhelmed their abilities to process that information. Multiple brands and product designs were reported to be annoying and overwhelming, often resulting in a blocked ability to process information and complete a desired purchase. The outcome was impulsive nonpurchasing, suggesting that spontaneous, unplanned purchases may be only one aspect of in-store impulsivity:

Too many choices ... Paper towels, pick a brand, then ya gotta pick a design. Food, I might be in the mood to eat it at a latter date but if I don't feel hungry or crave it right while I am in the store I won't buy it. Then I get home with very few groceries. I eat a lot of peanut butter and jelly sandwiches as a result of this problem. (Monica, 33)

I forget what I went for completely or if I am shopping for more than one item I will forget some of them. I often become frustrated and overwhelmed and come home with nothing. (Rachel, 48)

Overwhelmed by choices, ... get frustrated and walk out w/o buying anything-often. (Craig, 32)

Some respondents indicated that they selected products impulsively because they were frustrated or could not find what they were seeking. Such shoppers reported going to a destination with a shopping goal in mind, but upon arrival, not knowing which product to select, becoming confused by the amount of product comparisons or forgetting which brand or size to select. Their consumption impulsivity occurred when they were unable to make a choice. Their purchases were made based on some attribute that stands out, such as a graphic on the label, similar to Bonnie's report that she has "impulsive shopping habits, things are so brightly advertised" (age 28). In this case, it was not necessarily an urge for a particular item. In their eyes, impulse buying might be a reaction to failure to shop successfully. 


\section{UNNEEDED PURCHASES: SALES AND SPECIFIC PRODUCTS}

In contrast with the inability to complete planned purchases, another subtheme emerged regarding buying products that were not needed. They were attractive when in the store, when on sale, or when part of a product category of special interest. Something about the store environment attracted the ADDer to complete a purchase, often because of the reported appeal of a sale or the attraction of a particular high-interest product category. In addition, respondents reported purchasing regularly used items in bulk that were not needed at the present time:

Buying something on sale ... but some product that I know I wouldn't use. (Elaine, 51)

Very impulsive especially if there's a really good sale. Anything on sale. My mind races to think how I could use this product, whether for gifts at Christmas or just the fact I will use it, need it, and there may not be another good sale like this again Ex. Toilet paper. (Phoebe, 38)

I don't tend to buy useless items though. I may have plenty of cereal at home and have gone in to buy (again) milk, but walk out with two boxes of cereal. I may go in to Wal-Mart to buy a birthday gift for someone and come out with that and a something that I will put away for Christmas for my kids and the b-day gift. (Beth, 42)

The notion of a sale appeared to create a sense of urgency to complete a purchase for some future need, even if that need did not exist at present. Twenty-four respondents also mentioned being attracted by things that they see in the stores that they may be able to use at some time, because it caught their attention, was on sale, or looked like a good bargain. Megan, a 30-year-old female, reported that the things she bought impulsively were either " 1 ) buy one get one free, 2) half price this week, 3) $50 \%$ extra free, or 4) bargains bargains bargains."

In addition, 34 respondents indicated specific types of products that were likely to attract them as impulse purchases. These included typical impulse items found at checkout counters, such as candy, batteries, razors, and magazines. They also mentioned very specific categories of personal interest attracting them whenever they went shopping, such as beauty items, books, computer accessories, exercise equipment, ice cream, cheese, and housewares.

\section{Impulsive Product Assembly and Partial Use of Information}

Similar problems with product assembly or use were mentioned by the respondents as another significant subtheme expanding the consideration of impulsivity beyond point of purchase. Although they were confident in their own abilities to understand products and assemble them cor- 
rectly, respondents commented that complex directions or unnecessary information blocked their comprehension. In particular, they preferred that pictures or diagrams accompany written directions ( 17 respondents), that they have simple or concise instructions as opposed to long wordy descriptions (12 respondents), and be printed in step-by-step format (7 respondents). A few mentioned that the print was often too small, and that they began to read directions, got frustrated, missed important parts, and began assembly, only to be frustrated when they were unable to finish:

I always skipped right to buying something put it together and have extra parts left because I hate reading the directions. (Ross, 29)

Although I am fairly mechanical, I would rather have the finished product, or be putting it together for someone else. Long-term step by step is excruciating for me. My life is littered with projects in which all the ingredients, tools, etc. were purchased, but the actual product never appeared. (Edith, 49)

I either can't get the thing open or the directions are so detailed I just throw it away. (Gloria, 46)

They are confusing to me, and I try to skip the directions, or they are so small and black and white its hard to keep focused on them. (Bonnie, 28)

These comments support Dholakia's suggestion that consumption impulsivity is more encompassing than purchases made in the store setting, and can extend to product use and disposal. For instance, products requiring assembly can be approached impulsively as well, with little or no attention paid to directions, lists of parts, or other recommendations. Improper assembly based on impulsivity can result in products that do not work, cannot function, or potentially are dangerous.

\section{ADAPTIVE BEHAVIORS OF CONSUMERS WITH ADD}

The respondents indicated that certain types of behaviors were effective in their being able to shop successfully and manage their impulsivity in the marketplace. They provided examples of in-store resistance strategies, such as the first example below. In addition, their stories suggested that cognitive evaluation might also take place prior to an actual activation of the consumption impulse, as the second excerpt illustrates. That is, chronically impulsive individuals reported preplanning techniques to manage their impulsivity through their selection of shopping venue, such as shopping on-line or making master lists. Others planned to shop when stores are not crowded to try to avoid overstimulation. Similarly, several reported avoiding malls and superstores to avoid bright lights, loud music, crowds, and too many choices. 
For example, the respondents' store choices were often made based on the assessment of store simplicity and clear organization. The size of the shopping area, the number of stores, and the store layout were important factors to consider in forming an acceptable set of stores to patronize. Deliberate attempts at planning, the creation of rules of thumb, and lists of product information were also mentioned numerous times in attempting to create order in an otherwise chaotic shopping environment. ADDers were likely to be store-loyal and brand-loyal in trying to reduce the number of unexpected, in-store choices that they make ( 5 respondents). They tried to take deliberate control by asking for help if needed (7 respondents), making and trying to use lists (11 respondents), and hyperfocusing to avoid distractions ( 2 respondents).

It used to be that I totally avoided big shopping areas. OVERLOADvisual and audio. Now, I just pick my times-when it's quieter. I only go to the mall once or twice a year. I love catalogs ... Like I have to decide ahead of time not to buy. Don't ask me to figure out if I should in the store when it's calling to me and I can't prioritize, and there is no tomorrow. I let myself return stuff now, instead of just footing the bill out of embarrassment. This is where catalogs help me-to put some time between the thought and the action ... I do more "research" than I used to ... I have a three times rule. I will price comparison no more than 3 times, then make my decision. (Edith, 49)

When I'm shopping and I see things and put them in my cart without thinking - I've dubbed the behavior "The I want Syndrome". I see it-I want it. Go in to the grocery store I get every thing on my list but then I see some candles, a new type of mop, candy bars, a new collectable, name it-But now-I have taught my self a new trick. Items needed go thru the register first-The 'I wants' get a second thought and they get put back. Cashiers hate me. (Gloria, 46)

These comments indicate that ADDers are aware of their problems with impulsive consumption and can develop strategies to cope with them. When asked to report when shopping difficulties occur, they reported a variety of personal reasons, such as when they were tired, stressed, or overworked (nine respondents), physiological reasons such as low blood sugar or low medication levels (two respondents), or when they experienced overstimulation (three respondents).

\section{ASSESSMENT OF MARKETING STIMULI}

Given the confusions, distractions, and problems reported by the ADDers, they were asked one final question: "If you could speak to the Marketing Industry today, what would you want them to know about consumers with ADD?" Their responses reflected honesty regarding their reactions to marketing stimuli and their relationship to perceived impulsivity. 
Their themes included clarity and simplicity (17 respondents), consistency in messages ( 7 respondents), perceived distrust and perceived trickery (i.e., the perception that any information given to marketers would only make them try to get $\mathrm{ADDers}$ to spend more money, 13 respondents), reduction of overstimulation and use of appropriate cues (18 respondents), and logical organization in stores (9 respondents).

Show some respect for the way people learn and process. Make how you communicate connect us to each other and the natural world. Don't take advantage of our ADD weakness-impulsivity and distractiveness. Deserve our attention. (Edith, 49)

We need information and attributes clearly, concisely, and repetitively communicated. Category merchandisers should work to define common attributes across brands and manufacturers in a category. Standardization would benefit marketers, not detract from their ability to distinguish their products to the consumer. (Sally, 40)

We are impuslive, please dont market to make us broke and regretful. (Bonnie, 28)

Stop bombarding us with unnecessary information. I see every thing at the same time. After I finish shopping I have to nap. (Olive, 53)

ADDers were thoroughly aware of their strengths and weaknesses. They also knew what they needed in order to function successfully in the marketplace: simplicity, organization, and clarity. They mentioned needing simple directions and in-store information:

Directions should always be given both with words and by example so that all types of learners can easily decipher them. (Jennifer, 30)

Have simple step by step direction ... and pictures or diagrams. I am very visual, as I have noticed many of us are also. (Elaine, 51)

Simple, concise. Step by step instructions in straightforward language. Avoid busy graphics except where drawings clarify the assembly. (Sally, 40)

By helping ADDers reduce and manage product-use impulsivity, manufacturers are more likely to have satisfied customers.

\section{DISCUSSION}

This study has gathered the experiences of a sample of consumers whose behavior is characterized by high levels of impulsivity in many areas of 
their lives. Numerous themes emerged that provide additional insights into the conceptualization of consumption impulsivity. These themes provided some suggested directions for deeper understanding through further empirical examination. The themes included a common set of situations occurring in the stores that ADDers felt contributed to impulsive buying. For instance, they reported getting lost in many stores, being distracted by something new or different, and finding it very difficult to make comparisons and decisions. In addition, many reported making purchases impulsively in response to an item being on sale or being attractively positioned within the store.

To the authors' best knowledge, this is the first study relating attention deficit disorder to consumer impulsivity in marketing. Although previous researchers allude to "impulse buying tendency" (Beatty \& Ferrell, 1998; Rook \& Fisher, 1995), the present study identifies actual causes of impulsive consumption by relating impulsive consumer behavior to problems in information processing. As such, it not only contributes to understanding of consumer behavior, but also presents a kinder and gentler picture of consumers who are dealing with information overload and frustration, rather than what might be a more common stereotype of consumers who are simply out of control.

Many of the problems described above may not be specific to people with ADD. For example, confusion with assembly instructions is certainly not limited to the ADD segment. Similarly, simplicity of store layout and good usage of signs are given as reasons for the success of Kohl's department store; confusion in layout and signs caused loss of sales for J. C. Penney (Nelson \& Coleman, 2000). The experiences of ADDers as consumers may be one of magnitude rather than direction. Their experiences might inform us more fully, because their impulsivity is heightened because of their specific characteristics.

However, to the extent that ADDers are more sensitive to these issues and find their problems more overwhelming, they need to be considered as a special group to research. Their experiences of consumption impulsivity are rich with possibilities for further developing the understanding of how impulsivity is conceptualized and modeled.

\section{Research Implications for Future Studies of Consumer Impulsivity}

This study provides preliminary evidence that consumer impulsivity is a lifetime experience for persons with Attention Deficit Disorder. It suggests that impulsivity is the result of a combination of information-processing problems that creates a series of long-term effects that have received little attention from a consumer research perspective. The use of open-ended surveys allowed the respondents to convey their own styles, with multiple related stories that included several topics discussed in a simultaneous fashion. Asking the respondent to provide a narrative describing their own shopping experiences appeared to encourage a 
reporting style that allowed a consistent and recurring set of experiences and problems to emerge as perceived by the respondent. Although some of the reported experiences were expected, many of the specific problems reported by ADDers were unanticipated. Such issues include reported confusion and resentment caused by marketing stimuli such as merchandise rearrangement, frustration with specific types of noise and lighting, and the experience of getting lost in shopping environments.

The purpose of this study was to see if previously unidentified dimensions of consumer impulsivity could be found by examining the consumer behaviors of persons with $\mathrm{ADD} / \mathrm{ADHD}$, whose impulsiveness is a lifetime trait. Several themes emerged in this research that support the notion that consumer impulsivity is a multidimensional construct. Because a broader range of consumer impulsivity issues and problems has been uncovered, further study is recommended that compares and contrasts ADDers to persons without ADD. Such a study could potentially provide quantitative evidence whether these broader issues are also experienced by the population as a whole or if they are specific to persons with ADD. One interesting research focus would be whether those with ADD are more likely to engage in impulsive consumption than those without ADD. To this end, it would be useful to administer the Rook and Fisher (1995) nine-item measure of buying impulsiveness to all study participants.

Although the prevalence of impulsivity may or may not differ between ADDers and non-ADDers, it is expected that the causes of impulsivity would differ. Also, because distractibility and lack of organization skills are special traits of ADDers, the results of impulsive consumption, such as not returning unneeded items, are likely to be more severe among ADDers than non-ADDers.

In order to provide guidelines for future research, a series of propositions is presented that compare ADD consumers and non-ADD consumers. The propositions are divided into three sections. First, precursors to impulse purchases are discussed. These propositions include differences in information processing in $\mathrm{ADD}$ versus non- $\mathrm{ADD}$ consumers, as well as the effect of information-processing problems on impulsive purchases. Second, propositions are presented that compare the post-impulse-purchase behavior of ADDers and non-ADDers. Finally, a proposition is given that considers strategies for store selection used to avoid information overload by ADDers versus non-ADDers.

\section{Prepurchase Issues}

Overwhelming Stimuli. A common theme of ADD respondents in this study was feeling overwhelmed by stimuli. Such stimuli included visual and audio stimuli in the store setting, as well as product choices within product categories. This section includes propositions of different types of information overload, as well as different responses of ADDers to information overload. One ADD "solution" to the problem of overwhelming 
stimuli is to buy something quickly and leave the confusing environment. Therefore, it is expected that:

P1 (a) ADDers are more likely than non-ADDers to report feeling overwhelmed by the retail environment.

(b) ADDers are more likely than non-ADDers to report making impulse purchases as a result of trying to shorten the shopping experience due to a disagreeable retail environment.

Getting Lost and Not Finding Desired Products. Overwhelming stimuli in the retail environment can lead to the consumer getting distracted, and ultimately lost. Getting lost in stores can also result from relocation of departments or product categories. When consumers are lost, they encounter products that they did not plan to examine. The result can be impulse purchases.

P2 (a) Consumers with ADD are more likely than non-ADDers to report getting lost in retail stores.

(b) Consumers with ADD are more likely than non-ADDers to report making impulse purchases as a result of getting lost in stores.

Difficulties with Comparisons and Decisions. Overwhelming stimuli can occur within product categories. When many brands and brand extensions are offered to the consumer, ADDers may choose to simply grab a package, without much forethought, to escape the confusing environment.

P3 (a) ADDers are more likely than non-ADDers to report feeling overwhelmed by the varieties of brands and brand extensions available in retail environments.

(b) Because of information overload caused by variety in brands offered, ADDers are more likely than non-ADDers to make impulse purchases, without spending time making product comparisons.

Attraction of Sales and Specials. The flip side of the distractibility of ADDers is their ability to hyperfocus. Such hyperfocusing may create a welcome change from information overload. However, the ADD consumer needs to have a stimulus worth focusing on. When such a stimuli is available, they may be more likely to attend to it. Because attention is a precursor to behavior, such increased attention may be more likely to result in an impulse purchase. One way to gain the attention of ADDers is to have in-store sales and specials. 
P4 (a) ADDers are more likely to be attracted to in-store sales and specials than non-ADDers.

(b) ADDers are more likely than non-ADDers to make impulse purchases in response to in-store sales and specials.

Attraction for Creative Presentations in Store. Another type of stimulus that ADDers are likely to focus on and appreciate is creative presentations in the retail environment. Such attention is likely to result in impulse purchases.

P5 (a) ADDers are more likely than non-ADDers to pay attention to creative presentations in the retail environment.

(b) ADDers are more likely than non-ADDers to report impulse purchases from creative in-store displays.

Impulsive Nonpurchasing. Prior conceptualizations of consumer impulsivity typically focused on a resulting unplanned, spontaneous purchase. This study suggests that another potential outcome is impulsive nonpurchasing. Some respondents indicated that they frequently made shopping trips with a particular purchase in mind, possibly replacing a needed item or finding a specific gift. However, upon reaching their destination, they reported becoming frustrated by elements of the store environment and impulsively leaving without their planned purchase. Note that in this type of example, not making a purchase is unplanned and spontaneous, because it runs counter to the original intent of the shopper. Future studies might expand upon the full range of possible outcomes of in-store behaviors to determine whether impulsive nonpurchasing is a recurring and predictable component of consumption impulsivity. Impulsive nonpurchasing differs from consumption-impulse enactment and consumption-impulse dissipation proposed by Dholakia (2000), because it is an impulse enactment, not cognitive evaluation, that leads to nonpurchase of the planned product.

P6 ADDers are more likely than non-ADDers to report impulsive nonpurchasing when they face obstacles to making the purchase that they had planned.

\section{Postpurchase Effects of Impulse Buying}

Accumulation of "Unintended Inventory." The present findings suggest that much can be learned by examining the long-term effects of the impulsivity trait. Both the experts and the respondents described instances of making unnecessary and unplanned duplicate purchases over and over, resulting in an unintended inventory of certain products. They also reported the failure to buy certain needed items over and over. 
This is in contrast to compulsive buying, in which the same items or multiple items may be deliberately sought and purchased (O'Guinn \& Faber, 1989). Such unintended purchases were often made in direct response to the stimuli of being on sale.

P7 ADDers are more likely than non-ADDers to report making duplicate purchases that were not deliberately sought in stores, but purchased without thinking or referring to lists.

Nonreturns of Unsuccessful Purchases. Another pattern that surfaced was how unsuccessful purchases were handled. Although one might expect that most consumers return purchases that were made in error, some respondents stated that many of their impulse purchases were undesirable, but that they never got around to returning them or still had tags on them while they sat unused. They kept them, but just didn't use them. In addition, a different item was often purchased that still may not be desired, further building the unintended inventory. Future studies that examine the impacts of long-term impulsivity might also investigate whether ADD consumers also possess a larger amount of unused, stockpiled, or unreturned products versus non-ADDers.

P8 ADD consumers are more likely than non-ADD consumers to report nonreturn of purchases ultimately considered undesirable.

\section{Preplanned Impulse-Management Techniques}

Dholakia (2000) proposed that cognitive evaluation takes place during a shopping event, such as when the consumer is exposed to a particular product. As a reaction to the evaluation process, the volitional system of the consumer is utilized to retrieve resistance strategies that the consumer may have formed or learned to counter the consumption impulse.

The respondents suggest that chronically impulsive shoppers may also call the volitional system into play before entering a shopping situation. In fact, they reported deliberately choosing simple, well-organized, and less-stimulating retail environments in which they felt that impulsivity might be minimized or controlled. In addition, they reported planning in advance by utilizing catalogs as a strategy that reduces or eliminates the immediacy of the consumption impulse.

P9 ADDers are more likely than non-ADDers to prefer simple, wellorganized, less stimulating retail environments.

\section{Summary}

At some point in their lives, most consumers are likely to be distractible, disorganized, or impulsive in a specific attempt to make a purchase, assem- 
ble a product, or recall a preferred brand. During those times, consumer behavior will probably become less efficient, less effective, or less enjoyable. Informational cues may be misperceived and brand loyalties may be forgotten. Such problems are common for impulsive consumers, and possibly more common for ADDers. Analyzing the experiences of persons with demonstrated impulsivity may add insight into the concept and may give direction in presenting consumer information in understandable ways.

\section{CONCLUSION}

This study contributes to the research on impulsive consumption behavior of ADDers by offering evidence that such behavior is not simply a matter of being out of control. Rather, impulsive consumer behavior in ADDers appears to be a result of information overload, frustration, distraction, and other problems in information processing. Whether such precursors to impulsive consumer behavior also occur in non-ADDers remains to be researched. Perhaps, if there are differences, they are a matter of degree rather than kind. In any case, the current study suggests that consumer impulsivity is a more complex construct than previously discussed in the literature.

\section{REFERENCES}

Arias-Bolzmann, L., Chakraborty, G., \& Mowen, J. C. (2000). Effects of absurdity in advertising: The moderating role of product category attitude and the mediating role of cognitive responses. Journal of Advertising, 29, 35-61.

Atkins, M. S., \& Pelham, W. E. (1991). School-based assessment of attention deficit-hyperactivity disorder. Journal of Learning Disabilities, 24, 197-204.

Barkley, R. A. (1998). Attention deficit hyperactivity disorder. New York: The Guilford Press.

Barletta, M. (2003). Marketing to women. Chicago: Dearborn Trade Publishing.

Baumeister, R. F. (2002). Yielding to temptation: Self-control failure, impulsive purchasing and consumer behavior. Journal of Consumer Research, 28, 670-676.

Beatty, S. E., \& Ferrell, E. M. (1998). Impulse buying: Modeling its precursors. Journal of Retailing, 74, 169-191.

Biederman, J., S., Faraone, V., Spencer, T., Wilens, T., Mick, E., \& Lapey, K. A. (1994). Gender differences in a sample of adults with attention deficit hyperactivity disorder. Psychiatry Research, 53, 13-29.

Capon, N., \& Davis, R. (1984). Basic cognitive ability measures as predictors of consumer information processing strategies. Journal of Consumer Research, $11,551-562$.

CHADD. The disability named ADD [On-line]. Retrieved April 27, 2004, from http://www.chadd.org/fs/fs $1 . h t m$

Cobb, C. J., \& Hoyer, W. D. (1986). Planned versus impulse purchase behavior. Journal of Retailing, 62, 384-409. 
Coupey, E. (1994). Restructuring: constructive processing of information displays in consumer choice. Journal of Consumer Research, 21, 83-99.

Crawford, N. (2003). ADHD: A women's issue: Psychologists are fighting gender bias in research on attention-deficit hyperactivity disorder. Monitor on Psychology [On-line]. 34, 28. Retrieved 6 March, 2004, from http://www.apa.org/monitor/feb03/adhd.html

Dholakia, U. M. (2000). Temptation and resistance: An integrated model of consumption impulse formation and enactment. Psychology \& Marketing, 17, 955-982.

Dykman, R. A., \& Ackerman, P. T. (1991). Attention deficit disorder and specific reading disability: Separate but often overlapping disorders. Journal of Learning Disabilities, 24, 96-103.

FAQ's about AD/HD. (2003, July). Retrieved June 27, 2003, from http://www.additudemag.com

Gershon, J. (2002). A meta-analytic review of gender differences in ADHD. Journal of Attention Disorders, 5, 143-154.

Goodwin, R. E., \& Corgiat, M. D. (1992). Cognitive rehabilitation of adult attention deficit disorder: A case study. Journal of Cognitive Rehabilitation, 28-35.

Hallowell, E., \& Ratey, J. (1994). Driven to distraction. New York: Pantheon Books.

Harrell, W. L. (1994). Born or made. Success, 41, 14.

Holdnack, J. A., Moberg, P. J., Arnold, S. E., Gur, R. C., \& Gur, R. E. (1995). Speed of processing and verbal learning deficits in adults diagnosed with attention deficit disorder. Neuropsychiatry, Neuropsychology, \& Behavioral Neurology, 8, 282-292.

Jacoby, J., Speller, D. E., and Kohn, C. A. (1974a). Brand choice behavior as a function of information load. Journal of Marketing Research, 11, 63-69.

Jacoby, J., Speller, D. E., and Kohn Berning, C. A (1974b). Brand choice behavior as a function of information load-replication and extension. Journal of Consumer Research, 1, 33-41.

Jaska, P. (1996). What is ADD/ADHD? Interview with Peter Jaska, Ph.D., Menninger Clinic Seminar, Online Psych Forum [On-line]. Available: www.add.org Jaska, J. (1998). The national ADDA factsheet [On-line]. Available: www.add.org Johnson, R. D., \& Levin, I. P. (1985). More than meets the eye: The effect of missing information on purchase evaluations. Journal of Consumer Research, 12, 169-177.

Kivetz, R., \& Simonson, I. (2000). The effects of incomplete information on consumer choice. Journal of Marketing Research, 37, 427-448.

Kytle, R. (2001). Some researchers believe girls \& women have been overlooked, by field, Field, K., from Newsday, posted on the Manhattan Adult Attention Deficit Disorder Support Group, accessed, June 27, 2003, retrieved at: http://www.maaddsg.org/news_page_10.htm

Lord, K. R., \& Burnkrant, R. E. (1993). Attention versus distraction: The interactive effect of program involvement. Journal of Advertising, 22, 47-61.

MacInnis, D. J., Moorman, C., \& Jaworski, B. J. (1991). Enhancing and measuring consumers' motivation, opportunity, and ability to process brand information from ads. Journal of Marketing, 55, 32-53.

Malhotra, N. K., Jain, A. K., and Lagakos, S. W. (1982). The information overload controversy: An alternative viewpoint. Journal of Marketing, 46, 27-37.

Matlen, T. (1999). Personal communication.

McFeeters, L. (1999). Personal communication. 
Melini, C. B. (1987, February). Learning disabilities-Part 2. N.J.S.S.N.A. Newsletter, p. 3.

Meyvis, T., \& Janiszewski, C. (2002). Consumers' beliefs about product benefits: The effect of obviously irrelevant product information. Journal of Consumer Research, 28, 618-635.

Miles, M. B., \& Huberman, A. M. (1994). Qualitative data analysis. Thousand Oaks, CA: Sage Publications.

Monahan, R. (2003), personal communication.

Murphy, K. (1992, Fall/Winter). Coping strategies for ADHD adults. CHADDER, pp. $10-11$.

Nadeau, K. (1995). Life management skills for the adult with ADD. In K. Nadeau (Ed.), A comprehensive guide to attention deficit disorder in adults: Research, diagnosis, and treatment (pp. 191-217). New York: Brunner/Mazel.

Nadeau, K. (1999). Personal communication.

Nadeau, K., Littman, E., \& Quinn, P. (1999). Understanding girls with AD/HD. Silver Spring, MD: Advantage Books.

Nataraajan, R., \& Goff, B. G. (1992). Manifestations of compulsiveness in the consumer marketplace domain. Psychology \& Marketing, 9, 31-44.

Nelson, E., \& Coleman, C. Y. (2000, January 14). Re-tailing: America is shopping with abandon—Just not at J. C. Penney. Wall Street Journal, p. A1.

O'Guinn, T. C., \& Faber, R. J. (1989). Compulsive buying: A phenomenological exploration. Journal of Consumer Research, 16, 147-157.

Romaniuk, M. (1996). Impulsive spending and money management problems in ADD adults. In Eighth annual C.H.A.D.D. conference. Chicago: CHADD

Rook, D. W., \& Fisher, R. J. (1995). Normative influences on impulsive buying behavior. Journal of Consumer Research, 22, 305-313.

Ross, Jr., W. T., \& Creyer, E. W. (1992). Making inferences about missing information: The effects of existing information, Journal of Consumer Research, 19, 14-25.

Rostain, A. (1988). Assessing attention-deficit hyperactivity disorder. Philadelphia Child Guidance Clinic Forum, 3, 1-2.

Schroder, H. M., Driver, M. J., \& Streufert, S. (1967). Human information processing: Individuals and groups functioning in complex social situations. New York: Holt, Rinehart, and Winston.

Solden, S. (1995). Women with attention deficit disorder: Embracing disorganization at home and in the workplace. Grass Valley, CA: Underwood Books.

Stern, B. (1998). Narratological analysis of consumer voices in postmodern research accounts. In B. B. Stern (Ed.), Representing consumers: Voices, views, and visions (pp. 55-82). New York: Routledge.

Strauss, A., \& Corbin, J. (1998). Basics of qualitative research: Techniques and procedures for developing grounded theory. Thousand Oaks, CA: Sage.

Thompson, C. J., Locander, W. B., \& Pollio, H. R. (1989). Putting consumer experience back into consumer research: The philosophy and method of existential-phenomenology. Journal of Consumer Research, 16, 133-146.

Ukens, C. (1995). R.Ph. focuses on attention deficit disorder patients. Drug Topics, 139, 22.

Walliser, T. L. (1999). How women cope with ADD. Retrieved June 27, 2003, from http://abcnews.go.com/sections/living/DailyNews/add_women.html

Wolkenberg, F. (1986, October 11). Out of a darkness. New York Times Magazine, pp. $10 \mathrm{ff}$. 
Woods, S. P., Lovejoy, D. W., \& Ball, J. D. (2002). Neuropsychological characteristics of adults in ADHD: A comprehensive review of initial studies. The Clinical Neuropsychologist, 16, 12-34.

Young, S. (1999). Psychological therapy for adults with attention deficit hyperactivity disorder. Counselling Psychology Quarterly, 183-190.

Zametkin, A. J., Nordahl, T. E., Gross, M., King, A. C., Semple, W. E., Rumsey, J., Hamburger, S., \& Cohen, R. M. (1990). Cerebral glucose metabolism in adults with hyperactivity of childhood onset. New England Journal of Medicine, 323, 1361-1366.

Correspondence regarding this article should be sent to: Carol Kaufman-Scarborough, Rutgers University School of Business, 227 Penn Street, Camden, NJ 08102 (ckaufman@camden.rutgers.edu). 